\title{
Hvad siger lytterne egentlig? Om programtest af brugsradio
}

\author{
Af Kirstine Vinderskov
}

\begin{abstract}
Interessen for de kvalitative aspekter af radiolytningen er forst vokset frem, efter at Danmarks Radio det seneste årti for alvor er blevet udfordret af de kommercielle lokalradioer - specielt er konkurrencen om de unge lyttere skerpet betydeligt. Radioens karakter af baggrundsmedie har skerpet medieforskernes interesse for mediets funktionsaspekter: hvor og $i$ hvilke situationer $i$ hverdagen spiller radioen en rolle, og hvordan bruger lytterne radioen? Artiklen beskriver baggrunden for udviklingen fra kvantitative lytterstatistikker til brugerorienterede, kvalitative undersøgelser $i$ DR's medieforskning og giver derefter en erfaringsopsamlende oversigt over de anvendte metodiske varktojer og deres anvendelse i forhold til programtyper, lyttergrupper og brugssituationer.
\end{abstract}

\begin{abstract}
»Når man ser nyheder i fjernsynet, så har man planlagt det og sætter sig ned og ser det, men når man skal hører efter det i radioen, så skal det være spændende, for at man gider at høre efter, ellers bliver det sådan noget baggrundsstøj ... der skal være et eller andet, der fanger«
\end{abstract}

\section{(Naja 22 år Kolding)}

Lyttere har nogle klare forventninger til deres radio, og de kender deres egne lyttevaner godt.

Som afsender har det vist sig at være både nødvendigt og anvendeligt at inkorporere lytternes vurderinger og oplevelser af programmer og flader i de programmæssige afsender-overvejelser. DR-Radio's kvalitative medieforskning har på baggrund af et hverdags-perspektiv ${ }^{1}$ på radioforbruget bevæget sig hen imod analyser af konkrete programmer og flader. Formålet har været at kombinere en bredere sociologisk viden med en mere anvendelsesorienteret viden om oplevelsen og brugen af specifikke program-formater i radioen. Man kunne kalde det kvalitativ mediesociologi. I denne artikel gives et indblik i den måde, vi har bedrevet anvendelsesorienteret kvalitativ radioforskning på i DR.

\section{Baggrunden}

Radio-medieforskningen i Danmark har generelt været præget af et makro- fremfor mikro-perspektiv. Der er blevet talt og skrevet meget om radioka- nalers forbrug og markedsandele og ikke så meget om den oplevede lytterkvalitet af enkelte programmer, som det formuleres af lytterne selv. Der er flere årsager hertil, men nærliggende er det at pege på en kombination af den manglende konkurrencesituation for DR's vedkommende, og radioens natur som baggrundsmedie både for brugere og medieforskere.

I løbet af de seneste år er situationen dog blevet anderledes for DR-Radio med en stadig stærkere konkurrence fra lokalradioer og de nye medier især i forhold til de unge, men også andre målgrupper. Teorien om, at man med alderen bliver DR-lytter, gælder ikke nødvendigvis længere, og for en public service institution er det ikke nok kun at betjene bestemte dele af befolkningen. Alle danskere skal helst kunne finde noget, de kan bruge på en af DR's radiokanaler. Det er blevet nødvendigt at have et mere detaljeret kendskab til radioens funktion i hverdagen og lytternes kanalflade- og programpræferencer. Ikke mindst fordi DR-Radio kun får tilbagemeldinger fra lytterne i kvartaler i modsætning til de daglige TV-Meter tal.

TV-medieforskningen i DR-TV har gennem en årrække arbejdet systematisk med kvalitative program-test, og radioen har til en vis grad benyttet erfaringerne herfra, selvom der er en række grundlæggende forskelle på medierne. I 1997 blev den første prætest af et specifikt radioprogram gen- 
nemført i DR-Radio. Der blev lavet to fokusgrupper med lyttere, der repræsenterede programmets målgruppe alders- og interessemæssigt. De blev rekrutteret af et professionelt analyseinstitut på baggrund af TV's gode erfaringer hermed. Testen blev overværet af programmets redaktionsgruppe, der efterfølgende havde mulighed for at diskutere resultaterne. En praksis, der både metodemæssigt og rent pædagogisk har vist sig at være ganske nyttig. Der er fra starten en gennemsigtighed omkring selve den kvalitative metode, og det har bidraget til at give folkene bag programmerne en respekt for deres lyttere samt mulighed for løbende at implementere resultaterne i det redaktionelle arbejde. Siden er antallet af prætest og løbende test på radioen udfra denne skabelon steget støt. Ikke mindst antallet af løbende test der egner sig godt til radioen, hvor produktionsforholdene er på en sådan måde, at der kan justeres i programmerne, mens de sendes.

\section{Brugsradio}

Radio er et baggrundsmedie i modsætning til tv, der til en vis grad er et forgrundsmedie. Selvom tv-sening også er en aktivitet, der foregår sideløbende med andre aktiviteter indenfor hjemmets fire vægge. Radioen er i højere grad et individuelt medie, og man kan lytte mange andre steder end i hjemmet. For mange lyttere er det i bilen på vej til eller fra arbejde, at flest lytter mest koncentreret til radio ${ }^{2}$.

Man taler ikke om radio med hinanden, og radioforbruget flytter sig ikke fra dag til dag i samme grad, som tv-forbruget gør. Radio er nemlig ikke et holdningsmedie på samme måde, som tv er det (Teskeholdet én af undtagelserne). Selvom det kan være svært for de forståeligt nok meget indholdsfikserede programproducerende at forstå. Derfor taler vi i høj grad om brugsværdier, når vi taler om radio. En stor del af den typiske lytters radioforbrug foregår på et ubevidst plan en del af tiden og er det meste af tiden præget af, at man i sin lytning går til og fra. Derfor er langt den største del af radioudbuddet struktureret i flader fremfor programmer (med P1 som eneste undtagelse). Vi kalder det brugsradio. Det er den slags radio, jeg har koncentreret min interesse om og derfor vil fokusere på i denne artikel.
Kontekst og brugssituation er to centrale kodeord, når man vil i dybden med oplevelsen og vurderingen af specifikke radioprogrammer. Det nytter slet ikke på radio at betragte programmerne som løsrevne tekster uafhængige af tid og sted. Man må så at sige igennem hverdagen først. Et grundlæggende mantra for DR's kvalitative radioforskere er således, at »radioen skal fange folk i deres hverdag og ikke omvendt « ${ }^{3}$. Det er døgnets og hverdagslivets rytme, der er afgørende for, hvad lytteren får ud af og bruger radioen til og ikke i lige så høj grad selve programindholdet. »(...) Radio is "appropriated" by the individual much more than is any other medium because the attention she is able to give it is dictated not so much by the programmes it offers her as by the highly variable yet often rigid circumstances of her own life ${ }^{4}$.

Et af mange eksempler på hverdagens dominans over programindholdet ses i analysen af satire-serien Singletons, som DR's P3 forsøgte sig med lidt før kl. 8 på hverdagsmorgener i 1998. Her var en af lytternes anker, at seriens indhold ikke passede til lyttesituationen. Singletons byggede rent dramaturgisk som regel op til én afsluttende pointe, og den mente de fleste lyttere, at de ikke de ville kunne nå at høre, inden de skulle ud af døren. Og så var brugsværdien lille. Bilen blev også nævnt som det rette sted at høre radio som Singletons på den tid af dagen, fordi der her er lidt mere sammenhængende lyttetid end derhjemme, hvilket lytterne vurderede som nødvendigt for at få noget ud af satiren. $\mathrm{Og}$ det passede sendetidspunktet dårligt til.

Med brugsradioen i baghovedet kan man argumentere for, at individuelle dybdeinterview og observationer må være den mest valide måde at studere radiolytning på, fordi de tager højde for de afgørende brugssituationer, og for at lytningen ikke er en social aktivitet. Med dybdeinterviewet får man mulighed for at afdække den unikke lyttesituation og den enkelte lytters oplevelser og vurderinger af programindholdet. Observationen giver et indblik $\mathrm{i}$, hvad lytterne foretager sig, mens de lytter, men selvsagt ikke hvad de (ikke) tænker og føler. Man kan også argumentere for, at gruppe-interviewet med folk, der deler livsomstændigheder og lyttepræferencer koblet med en grundlæggende viden om lyttemønstre henover dagen og døgnrytme, kan give ligeså valide resultater. 


\section{Refleksive lyttere?}

Uanset hvordan man vender og drejer det, forudsætter vi, at folk kender deres egen lytte-adfærd godt og er i stand til at forholde sig refleksivt til den. På den måde kan man sige, at vi i analysen stoler på, at den »account«, lytterne giver os, svarer til virkeligheden, selvom vi også er opmærksomme på, at især nogle typer af lyttere gerne vil fremstå på en særlig måde (der er nogle programmer og kanaler, det er »bedre « at lytte til end andre) sådan at det nærmere er holdninger end adfærden, der afspejles i deres udsagn. $\mathrm{Og}$ at andre lyttere stort set ikke vurderer indholdet $\mathrm{i}$ radioen som sådan, men derimod det de kan bruge det til. Et andet problem er faren for at gøre noget vigtigt som $\underline{\text { ikke er }}$ vigtigt ved at fokusere på det, sådan som vi jo gør med radioprogrammerne i disse kvalitative undersøgelser. Så at sige gøre baggrundsmediet til forgrund. Disse paradokser lader sig ikke sådan løse én gang for alle, men er nødvendige at forholde sig til i forhold til den enkelte undersøgelses forskellige faser. Man må tage højde for det i forhold til sit metodevalg, interviewteknik, sit fokus og ikke mindst i analysen. Helt grundlæggende er det dog, at netop fordi lytteren tilpasser radioen til sig liv og ikke omvendt, må vi tage udgangspunkt i lytterens eget liv. Og hvem kender det bedre end lytteren selv.

\section{Gruppeinterview}

Vi vælger ofte fokusgrupper - af flere årsager. For det første giver gruppen mulighed for at italesætte radiobrugen, og det viser erfaringen, at lytterne godt kan. I gruppen inspireres lytterne af hinandens »accounts«, og vi får mulighed for at komme lidt længere, fordi der ofte kommer flere nye temaer på bordet end ved enkeltpersonsinterview, hvor intervieweren ofte må være lidt mere styrende. Vi har mange eksempler på, at lyttere sætter hinanden i gang og bringer diskussionen videre, når vi laver associationslege, kinesiske portrætter eller benytter andre projektive teknikker. For det andet er det tidsbesparende, fordi man gennem 2-3 grupper kan udgrænse de væsentligste oplevelser og vurderinger af et givent program indenfor målgruppen og en eventuel reference-el. parallelgruppe relativt hurtigt. I gruppeinterview benytter vi ofte personlige semanter, som udfyldes individuelt, og som danner udgangspunkt for diskussionen og giver et fingerpeg om, hvorvidt deltagerne har ændret holdninger undervejs. Vi bruger også opmærksomhedskurver, der fungerer særdeles godt i forhold til radiolytningen, der netop er præget af, at man i sin opmærksomhed går til og fra. Vi ser ind imellem, at kurverne i større eller mindre grad afspejler lytternes adfærd og derfor ikke altid stemmer overens med, hvad de senere erklærer er særdeles vigtigt at bringe i fx. en nyhedsudsendelse. Indslaget skal være der, men de lytter ikke efter. Sådanne modsætninger inddrages i gruppediskussionen og ikke mindst i analysen, fordi det har en indflydelse på, hvordan man skruer sin nyhedsudsendelse sammen bedst muligt. Andre modsætninger forsøger vi derimod at nedtone, fordi de ikke på samme måde er direkte anvendelige i forhold til det givne program.

Så vidt muligt rekrutterer vi homogene grupper. På den måde adopteres den sociale status, deltagerne har udenfor gruppen ikke ind i gruppen og påvirker resultaterne og gruppedynamikken, fordi fx. direktøren er mere dominerende end rengøringsassistenten. »It appears that the more socially and intellectually homogeneous the interview group, the more productive its reports. Correlatively, when the members of the group are of widely disparate social status or differ greatly in intelligence and educational attainments, the interview tends to be doubly damaged. Interviewees of widely differing social status often make comments or refer to experiences which are alien or meaningless to the rest ${ }^{5}$.

I radiosammenhænge har vi dog eksperimenteret med dette, fordi vidt forskellige faggrupper kan have sammenfaldende radiovaner: De står fx. op samtidigt om morgenen, er lige gamle og lytter derfor til Godmorgen P3. På den måde adskiller radiomålgrupper sig fra tv's ved ikke at lade sig definere lige så rent i forhold til uddannelse, værdier og deraffølgende program/kanal-præferencer. Alder er mere afgørende for, hvornår og hvad man lytter til end fx. holdning. Derfor er livstilsrekrutteringer heller ikke ligeså udslagsgivende i forhold til radiolytning som i forhold til tv-sening.

I uhomogene grupper, hvad angår social status, men ikke lytte-vaner, har vi bevidst nedtonet statusforskellene og har i stedet fokuseret på det, de havde til fælles - nemlig radiovanerne. Især deltagere med høj ekstern status får afsløret deres baggrund alligevel, ofte som et forsøg på at give et personligt synspunkt en mere generel legitimitet. Andre bruger deres arbejdssituation som 
forklaringsbaggrund for deres lyttemønstre. Hvis vi forsøger at nedtone eventuelle statusforskelle i gruppen, forholder det sig modsat med hverdagens organisering. Vi bruger den første del af interviewet på at afdække, hvilken hverdag deltagerne har: Hvornår står de op, har de travlt, hvordan kommer de til arbejde, lytter de, mens de arbejder, hvornår og hvordan kommer de hjem, hvornår laver de mad og spiser, går de ud om aftenen, hvornår går de i seng o.s.v.

Lyttesituationerne sættes i relation til radioen og den funktion, den har i forhold til de hverdagssituationer, man befinder sig i på en typisk dag. Først derefter kommer preferencer i forhold til programmer og flader. Starter man omvendt, bliver der som regel påfaldende stille i gruppen. Ikke fordi lytterne ikke har noget at sige, men fordi man spørger forkert. Et eksempel er, at mange især unge lyttere siger, de aldrig hører radio. Men hvis man spørger til forskellige situationer, de befinder sig i i løbet af en dag, husker de pludselig, at de lytter til ANRHitfm, når de kører i bil.

\section{Overlagt uhomogenitet}

Uhomogene grupper har vi forsøgt i forhold til afdækningen af kanalpræferencer. Vi har således med succes sat lokalradiolyttere sammen med $\mathrm{fx}$ P3 lyttere, fordi netop forskellen på stationerne og kendskab til potentielle lytteres præferencer var fokus for undersøgelsen. Sådanne problemstillinger og deraf følgende rekrutteringer er mest benyttet i forhold til unge lyttere, hvor DR's mankodækning ${ }^{6}$ er størst. Et eksempel er P3-nyhederne, der blev prætestet i 6 fokusgrupper rundt omkring i landet. Disse grupper var sammensat således, at de alle bestod af lyttere i samme aldersgruppe, (23-28 årige som modsvarer midten af målgruppen), men derudover adskilte de sig i forhold til geografi og kanalpræference. På den måde talte vi med et bredt spektrum af lokalradiolyttere såvel som P3 lyttere og med lyttere, der kombinerede $P 3$ med en eller flere lokalradioer.

Man kan sige, at fordi radio i modsætning til tv tilegnes individuelt, mere eller mindre ubevidst, mere eller mindre opmærksomt og som regel ikke er en social aktivitet, er fokusgruppen en meget kunstig setting at tale radiobrug i. Og at man burde foretage supplerende observationsstudier eller etablere vir- kelighedstro lyttesituationer: Udstyre lytteren med en opvaskebørste, støvsuger, avis eller bil. Erfaringen har dog vist os, at dels er folk gode til at forholde sig til deres faktiske lytteforhold i fokusgrupperne og vurderer programmerne på den baggrund, dels har vi et bredt kendskab til lytteradfærden fra omfattende døgnrytmeundersøgelser. Men vi benytter også enkeltpersonsinterview, når det synes nødvendigt. En del af setting-problematikken løses ved at tale med lytterne enkeltvis i vante omgivelser. Vi har dog endnu ikke lavet interview i bilen eller på arbejdspladsen, men begrænset os til hjemmet.

\section{Dybdeinterview}

Dybdeinterviewet er især blevet brugt i ikke-prætest sammenhænge, hvor tidshorisonten som regel er for knap til disse mere tidskrævende studier. Et eksempel er en analyse af Radioavisens henvendelsesform, som vi lavede i $1998^{7}$. Dette er også et eksempel på en segmentrekruttering. Da Radioavisen skal henvende sig bredt til alle dele af befolkningen, besluttede vi at rekruttere bredt demografisk og segmentmæssigt. Vi fandt interviewpersoner rundt om i landet og havde repræsentanter fra de fire verdenshjørner i Kompasrosen ${ }^{8}$ og fik derved demografien »foræret«, da segmenterne også afspejler alder og uddannelse. Ønsket om at komme rundt i alle segmenterne var også én af grundene til, at vi besluttede at lave enkeltpersonsinterview. Alle interview blev gennemført $\mathrm{i}$ interviewpersonernes hjem, hvor de efter en indledende snak om deres nyhedsforbrug blev bedt om at lytte til udvalgte Radioaviser, alt imens de tegnede en opmærksomhedskurve. Vi benyttede også eksempler fra andre typer nyhedsformidling end Radioavisens for at sætte tankerne i gang hos de enkelte lyttere. Disse interview var generelt svære at gennemføre dels p.g.a Radioavisens »urørlighed« og dels p.g.a. radioens natur som baggrundsmedie (om analysens resultater se nedenfor).

Når der er problemer med et radioprogram eller en flade, hænger det ofte sammen med tidspunktet og formen og i mindre grad med indholdet. Men det betyder ikke, at indholdet er fuldstændig ligegyldigt. Tværtimod har det en lang række konsekvenser for måden indholdet formidles på, hvis det skal fungere bedst muligt udfra et lyttersynspunkt. 


\section{Eksempler på resultater og deres anvendelse}

Vi laver anvendelsesorienteret medieforskning $\mathrm{i}$ DR, og det betyder, at resultaternes brugbarhed i programudviklingen er altafgørende. Derfor er formidlingen af resultaterne noget, vi lægger stor vægt på. Vi fremlægger altid hovedresultaterne mundtligt hurtigst muligt, og efterfølgende kommer en mere uddybende rapport med detaljerede resultater og citater for at sikre det videre liv.

Der er blevet lavet en del analyser på nyhedsområdet gennem tiderne, og i det følgende vil jeg give to eksempler på sådanne analyser fra to forskellige måder at formidle nyheder på.

Institutionen Radioavisen trængte til et eftersyn ikke mindst i forhold til henvendelsesformen. I forbindelse med en opprioritering af efterkritik-procedurerne blev det besluttet at gennemføre en kvalitativ lytterundersøgelse med fokus på forståelighed, relevans og formidling i Radioavisen. Målet var gennem et kendskab til lytternes holdninger og vurderinger at få en modtagerorienteret terminologi at diskutere Radioavisens henvendelsesform ud fra.

Netop Radioavisen er et godt eksempel på, at radio er svært at tale om, medmindre man aktualiserer brugsradioperspektivet. Folk, og det går på tværs af uddannelse, kan ikke umiddelbart genfortælle, hvilke indslag de lige har hørt i en Radioavis. Det handler ikke kun om indholdet i udsendelsen, men også om mediets natur som beskrevet tidligere. At Radioavisen af mange betragtes som en urørlig institution, gør det ikke lettere. Det sætter så meget desto større krav til relevansen, men betyder også at Radioavisen også har en brugsværdi blot ved at være der.

Undersøgelsen viste hurtigt nogle grundlæggende forskelle blandt lytterne og havde afgørende indflydelse på den opfattelse, lytterne i udgangspunktet havde af Radioavisen. Det betød, at vi opdelte lytterne i forhold til deres informationsstyrke. Igennem analysen kom vi altså til at arbejde med en gruppe af informationsstærke, der typisk repræsenterede de nordlige segmenter og en større gruppe af lyttere fra de sydlige segmenter, der repræsenterede de informationssvage.

En af hovedpointerne var, at de informationssvage ikke i lige så høj grad følte sig serviceret af $R a^{-}$ dioavisen. De følte ikke rigtig, at »de fik noget at vide«, når de hørte Radioavisen. En anden pointe i undersøgelsen er, at væsentlighed defineres vidt forskelligt i de forskellige segmenter. Radioavisen som afsender har nogle klassiske nyhedskriterier for væsentlighed, som ligger tæt op af de informationsstærkes. Her er et perspektiv oppefra (vigtigt for samfundet) relevant i modsætning til de informationssvage, der i højere grad synes, et perspektiv nedefra (vigtigt for mig) er mest relevant. Disse grundlæggende forskelle har stor indflydelse på, hvordan man oplever de informationer, Radioavisen viderebringer.

En tredje pointe fra undersøgelsen var, at både informationssvage og -stærke havde forståelighedsproblemer i forhold til de samme indslag, de informationsstærke kunne bare abstrahere fra det: Indslaget er ikke relevant (for mig), men derimod vigtigt (for samfundet). For de informationssvage var indslagene enten relevante (for mig) eller ikke relevante(for mig).

Herudover var der en lang række konkrete tilbagemeldinger på de enkelte indslag, som gav input til Radioavisens videre arbejde med vinklinger, særlige stofområder (EU fx.), prioriteringer, brug af kilder og udviklingen af et decideret værtsskab væk fra den mere anonyme oplæserrolle, lytterne i høj grad mente prægede Radioavisen.

\section{P3-Nyhederne}

P3Nyhederne, der kunne høres for første gang d. 2 januar 2001, og som vel egentlig er det første reelle brud på Radioavisens mangeårige nyhedsmonopol på landsdækkende nyheder, blev prætestet i en række fokusgrupper inden udsendelsesstart.

Baggrunden for at lancere P3-Nyhederne var et ønske om at kanalformattere nyhederne som den øvrige flade. Derfor er P3-nyhedernes målgruppe den samme som P3's (12-35 årige med fokus på de 25-35 årige) og altså ikke hele befolkningen, som det er tilfældet med Radioavisen. Helt afgørende for projektet var at finde ud af, hvad DR-Nyheder kunne tillade sig uden at sætte troværdigheden over styr. Og svaret var, at vi, efter en vis tilvænningsperiode, kan tillade os en hel del mere, end vi selv - og til en vis grad lytterne - tror.

Udsendelserne skulle produceres af DR-Nyheder, men i en selvstændig redaktion. Der blev produce- 
ret tre forskellige dummy-versioner, som varierede på formsiden og i emnevalg. De blev afspillet i rotation i grupperne, og det viste sig hurtigt, at der var en rækkefølgeeffekt. Typisk blev den først afspillede version vurderet dårligst og den sidst afspillede bedst. Det gav os en formodning om, at lytterne skulle vænne sig til en anderledes nyhedsformidling end Radioavisens, på P3. Dette gjaldt også, selvom de ikke var dedikerede brugere af Radioavisen (og dermed automatisk kritiske overfor andre måder at formidle nyhedsstoffet på fra DR).

Et hovedresultat var, at $P 3$-nyhederne af målgruppen blev vurderet som et godt alternativ til både de »useriøse « lokalradioers nyhedsformidling og $R a^{-}$ dioavisens lidt »stive« henvendelsesform. Flere mente, P3-nyhederne kunne få dem til at lytte efter i modsætning til Radioavisen, som de ikke oplevede henvendte sig til dem. Lyttergrupperne mente, at P3-nyhederne havde deres egen sound og derfor lød som noget helt nyt og anderledes end »typisk DR «. Den tætteste sammenligning, de kunne komme med, var lokalradioernes nyheder og især form bare i en bedre udgave.

Et andet resultat var, at lytterne - også de unge har nogle særlige forventninger til DR om seriøsitet, troværdighed og høj kvalitet. Nogle forventninger de ikke i samme grad har til lokalradioerne. Det er i øvrigt noget, vi generelt oplever fra både seere og lyttere især i forhold til nyheder, men også til øvrige DR-programmer.

Endelig blev det tydeligt, at uanset, hvor gode og relevante P3-nyhederne vurderes isoleret set, er det i denne målgruppe særdeles afgørende, hvilken flade nyhederne ligger i, og hvilken musikprofil den har. Denne lyttergruppe går ikke efter nyhederne alene.

I forhold til P3-nyhedernes form lagde lytterne vægt på længden. De lange indslag blev typisk vurderet mest negativt. Der bør ikke være for mange vinklinger, og der skal være klart fokus på konsekvenser. Herudover blev der lagt vægt på aktualitet. Der skal være sket noget nyt, ellers har historien ingen interesse. Det gælder generelt, men især i forhold til det man kan kalde føljeton-nyheder (fx. EU-stoffet). Rent metodisk blev aktualitetsproblematikken ekstra tydelig, fordi nyhederne af praktiske årsager var forproducerede og derfor for flere af historiernes vedkommende var »gamle« nyheder. Det tydeliggjorde dog så meget desto mere en anden pointe, nemlig at indslag, der »vender tingene lidt på hovedet«, fanger opmærksomheden blandt lytterne (fx. ny og overraskende vinkel på en kendt historie).

Redaktionen brugte resultaterne i færdigudviklingen af P3-nyhederne, og lytternes vurderinger og oplevelser indgår i den løbende kvalitetssikring af udsendelserne, der i dag sendes hver time mellem 12-17:00 alle hverdage på P3.

\section{At tage lytterne alvorligt}

I dag er modtagerne med på råd fra et programforslag udvikles, testes, sendes og senere evalueresi forhold til, hvordan det så gik. På den måde er lytterne inkorporeret $\mathrm{i}$ afsenderovervejelserne lige fra starten. Udfordringen ligger $i$ at kombinere den viden om lytterkvalitet, som de skitserede studier giver med den kvalitet, DR-Radio som afsender skal og vil stå for. Det kræver veldefinerede og gennemdiskuterede programmæssige målsætninger og en klar konsekvens, hvis de ikke opfyldes. Et program skal kunne tages af eller udviklingsforløbet startes forfra, hvis konceptet i sin grundidé ikke fungerer, og hvis justeringer altså ikke er nok. For at sikre denne konsekvens i forhold til programplanlægningen og det redaktionelle ansvar herfor er medieforskningen en del af Chefredaktionen, hvor de ansvarlige redaktører sidder. Medieforskningen indstiller, og redaktøren træffer de endelige redaktionelle beslutninger på programmets og ikke det produktionelle eller personalemæssiges præmisser. Fokus er på programmerne og brugen af dem.

\section{Fremtidige udfordringer}

De yngre målgruppers medieadfærd bliver en af de helt store udfordringer at følge for medieforskningen i fremtiden. Selvom broadcast-lytningen generelt set langt overstiger web-lytningen og sikkert vil gøre det mange år fremover, gælder det ikke nødvendigvis i bestemte målgrupper og indenfor bestemte genrer. Unge lyttere kunne fx. finde på helt eller delvist at fravælge al snakken i æteren til fordel for rene musikkanaler fx. på nettet. DR streamer i dag radio på nettet og har senest lanceret den musikformatterede net-kanal Skum i et forsøg på at interessere netop de yngste lyttere, der i 
høj grad fravælger DR til fordel for kommercielle musikkanaler.

Sammenholdt med et øget udbud på tværs af mediegrupper følger en eller anden grad af øget individualisering i mediebruget. I hvilken udstrækning individualiseringen vil ske, og hvilke konsekvenser det vil have for medieforbruget er vanskeligt at spå om. For radioens vedkommende bliver det nødvendigt at udvikle mere dynamiske og løbende målemetoder end de kvartalsvise lyttertal og konstant udbygge den kvalitative metodekasse til fx. også at kunne analysere netindhold. For DR's vedkommende bliver en stor udfordring at finde konsistente metoder, der både kvantitativt og kvalitativt kan følge brugeren på tværs af medierne, når og hvis den floworienterede brug af medierne gradvist forsvinder. For slet ikke at tale om at kunne levere det rette programmæssige indhold.

\section{Noter}

1. Jvf. Niels- Aage Nielsen: »The Listener is the Medium. - A Research Project in Danmarks Radio.« DR, Development Department , 1995 og Bent Steeg Larsens specialeafhandling fra KUA, Film \& Medievidenskab Lyden af Hverdag, 1995.

2. Diverse undersøgelser gennemført af DR-Radio's medieforskning.

3. Se Niels-Aage Nielsen op.cit.

4. Andrew Crisell: Understanding Radio side 213, Routledge 1995.
5. Robert K.Merton: The focused interview side 137, The free press London 1990.

6. Manko-dækningen udtrykker den del af befolkningen der ikke lytter eller ser DR.

7. Se i øvrigt Ib Poulsens Radioavisens forståelighed, DR 1988 og Uge 39-en eksperimentaluge på Radioavisen, DR 1992.

8. Se i øvrigt pjece om GallupKompas og radiolytning, Radioens medieforskning 1998.

\section{Litteratur}

Crisell, Andrew: Understanding Radio. Routledge 1994.

Larsen, Bent Steeg: Lyden afhverdag, en undersogelse af radiobrug og hverdagsliv. Specialeafhandling, Film \& Medievidenskab Kbh's universitet 1995.

Poulsen, Ib: Radioavisens forståelighed. DR 1988.

Poulsen, Ib: Uge 39 - en ekspereimentaluge på Radioavisen. DR 1992.

Nielsen, Niels-Aage: The Listener is the Medium. - A Research Project in Danmarks Radio. DR 1995.

Nielsen, Niels -Aage og Kirstine Vinderskov: GallupKompas og radiobrug. DRUda 1998.

Merton, Robert K.: The focused interview, a manual of problems and procedures. The Free Press 1990.

Diverse interne forskningsrapporter fra DRRadios medieforskning.

Kristine Vinderskov er medieforsker i DR TVChefredaktionen 